\title{
Both fractional exhaled nitric oxide and sputum eosinophil were associated with uncontrolled asthma
}

\author{
Jie Gao \\ Zhaocheng Chen \\ Xiang Jie \\ Ruihua Ye \\ Feng Wu \\ Department of Respiratory Medicine, \\ The Third People's Hospital, \\ Guangzhou Medical College, Huizhou, \\ People's Republic of China
}

This article was published in the following Dove Press journal: Journal of Asthma and Allergy

Background: Sputum eosinophil and fractional exhaled nitric oxide (FeNO), noninvasive biomarkers of local eosinophilic airway inflammation, can be used to assess asthma outcome. Nevertheless, the clinical application of the association between FeNO and sputum eosinophil is controversial. The aim of the study was to investigate the predictive relationship between FeNO and sputum eosinophil in uncontrolled asthmatic patients and the correlation between sputum eosinophil and FeNO in bronchial reversibility and bronchial hyperresponsiveness (BHR).

Methods: A total of 69 uncontrolled asthmatic patients were included in the study. All patients underwent a clinical assessment on the same day as follows: FeNO, spirometry with BHR or bronchodilator reversibility test and induced sputum in turn. Eosinophilic airway inflammation was defined as sputum eosinophil percentage ( $\geq 2.5 \%) /$ FeNO level ( $\geq 32$ parts per billion [ppb]). Results: FeNO level and sputum neutrophilic percentage were higher in the sputum eosinophilia group compared to those without ( 49 versus $27, p=0.011 ; 71.12$ versus $87.67, p=0.012$, respectively). Sputum eosinophil percentage was higher with raised FeNO level compared to those without ( $10.3 \%$ versus $2.75 \%, p=0.03)$. A significant correlation was observed between sputum eosinophil percentage and FeNO level $(r=0.4016 ; p=0.0006)$. There were no significant relationships between sputum eosinophilic percentage and provocative dose $\left(\mathrm{PD}_{20}\right) / \Delta \mathrm{FEV}_{1}$ (improvement in a forced expiratory volume in 1 second $\left[\mathrm{FEV}_{1}\right]$ after $400 \mu \mathrm{g}$ of salbutamol), FeNO levels and $\mathrm{PD}_{20} / \triangle \mathrm{FEV}_{1}$. The FeNO level of $35.5 \mathrm{ppb}$ was effective in assessing sputum eosinophilia, with a receiver operating characteristic area under curve (AUC) of 0.707 ( $p=0.011 ; 95 \%$ confidence interval [CI] $0.573-0.841$ ), and $4.36 \%$ was the best diagnostic cutoff value of sputum eosinophil percentage for the FeNO level of 32 ppb (AUC 0.721; 95\% CI 0.59-0.852).

Conclusion: FeNO level can accurately detect eosinophilic asthma but has limited value to assess noneosinophilic asthma in uncontrolled stage. Further studies are required to validate the use of FeNO level to determine an optimal cutoff for sputum eosinophilia that could be used in clinical practice. Keywords: FeNO, sputum eosinophil, bronchial reversibility, BHR, asthma

\section{Introduction}

Assessment of airway inflammatory phenotype can help to optimize the diagnosis and clinical control of disease. The eosinophilic phenotype identified patients who will show a good response to corticosteroids ${ }^{1}$ and TH2 immunomodulators ${ }^{2}$ better than noneosinophilic phenotype in asthma. Eosinophilic airway inflammation can be measured through the airway biomarkers by sputum eosinophil. Fractional exhaled nitric oxide (FeNO) is generally considered as a surrogate biomarker of sputum eosinophilia. ${ }^{3}$ Both are considered as direct, reliable, sensitive, simple and repeatable methods for assessing inflammatory phenotype, which are widely used in clinical practice.
Correspondence: Feng Wu

Department of Respiratory Medicine, The Third People's Hospital, Guangzhou Medical College I\# Xuebei Avenue, Huizhou 5I6002, Guangdong, People's Republic of China

$\mathrm{Tel}+86$ I35 02436132

Fax +867522359825

Email huizhouwufeng@126.com 
However, airway inflammation in asthma can be predominantly eosinophilic or noneosinophilic, including neutrophilic, mixed granulocytic and paucigranulocytic. Neutrophilic and paucigranulocytic asthma could not be detected by elevated FeNO. Furthermore, the usefulness of incorporating FeNO into usual methods to determine the level of asthma control has shown inconsistent results, with a lower reliability as compared with induced sputum. ${ }^{4}$ In 2016, the normal reference value of induced sputum cytology in China was defined as a sputum eosinophil percentage of $\geq 2.5 \%$, and an increase in FeNO level of $\geq 32$ ppb was identified as airway eosinophilia. ${ }^{5}$ Nevertheless, the association between FeNO and sputum eosinophil is controversial.

The aim of the study was to 1) evaluate the correlation between FeNO and sputum eosinophil, 2) determine the accuracy of the biomarkers as indicators of eosinophilic inflammation and 3) assess the relationship between sputum eosinophil/FeNO, bronchial hyperresponsiveness (BHR) and bronchodilator reversibility in asthmatic patients.

\section{Methods}

\section{Study design and patients}

Patients diagnosed with asthma who visited The Third People's Hospital of Guangzhou Medical College in Huizhou from April 2016 to June 2017 were retrospectively enrolled in this study.

Asthmatic patients were diagnosed according to a clinical history of cough, wheezing, chest tightness or shortness of breath, as well as the presence of variable airflow obstruction (BHR or bronchodilator reversibility), based on the 2017 Global Initiative for Asthma (GINA) guidelines. ${ }^{6}$ None of them had a history of chronic obstructive pulmonary disease (COPD) or previous doctor-diagnosed asthma-COPD overlap. All patients have not used any leukotriene modifier and corticosteroid in the previous 12 weeks. The study did not include any pregnant patients. Included patients were initially diagnosed with uncontrolled stage.

The patients who had a confounding pulmonary comorbidity, such as a pulmonary tuberculosis, an interstitial lung disease and a lung cancer or a pulmonary infection, and a cognitive impairment that may affect the collaboration or comprehension of the study were excluded.

\section{Ethics statement}

The institutional review board of The Third People's Hospital of Guangzhou Medical College in Huizhou approved the study protocol and absolved the need for written informed consent from patients as the study was a retrospective study with personal identification data anonymized.

\section{Assessments and study procedures}

All the following tests were performed on the same day: FeNO, pulmonary function test (PFT) with BHR or bronchodilator reversibility test and induced sputum in turn. Clinical variables were recorded in participants.

\section{Measurement of FeNO level}

FeNO was measured before spirometry according to the guidelines in the user manual of the NO electrochemical equipment (NIOX VERO; Aerocrine AB, Solna, Sweden). Patients are required to refrain from eating, drinking and smoking for at least 1 hour prior to the FeNO measurement. Patients were instructed to inhale NO-free air to total lung capacity and immediately exhale fully into the device at a sustained flow rate of $50 \mathrm{~mL} / \mathrm{s}$ for 6 or 10 seconds and resulted in display of a FeNO level. ${ }^{7}$ A significant increase in FeNO was considered if the FeNO level was $\geq 32$ parts per billion (ppb). ${ }^{5}$

\section{PFT}

Airway limitation was performed using the Lung Function Machine (MS-pneumo+aps; JAEGER, Friedberg, German) by the experienced technician in accordance with the 2014 recommendations of the Chinese National Guidelines of Pulmonary Function Test. Percentage predicted values (\%pred) were calculated based on the reference values for healthy Chinese adults. All patients were required to undergo PFT in a reproducible way, and the best values were retained. ${ }^{8}$

\section{BHR test}

PFT values were assessed prior to methacholine challenge. Patients with a forced expiratory volume in 1 second $\left(\mathrm{FEV}_{1}\right) \%$ pred of $<60 \%$ were excluded from the BHR test (at baseline). The breath dosimeter method was used according to the published guidelines from the Chinese National Guidelines of Pulmonary Function Test. The test sequence included five steps: $0.9 \% \mathrm{NaCl}$ only, $0.078 \mathrm{mg}, 0.312 \mathrm{mg}$, $1.125 \mathrm{mg}$ and $2.504 \mathrm{mg}$. Airway responsiveness is expressed as the provocative dose of methacholine causing a $20 \%$ reduction in $\mathrm{FEV}_{1}$ (provocative dose $\left[\mathrm{PD}_{20}\right]$ ), and the positive response was defined as $\mathrm{PD}_{20} \leq 2.504 \mathrm{mg}$ (between $0.9 \%$ $\mathrm{NaCl}$ and $2.504 \mathrm{mg}$ ). ${ }^{8}$

\section{Bronchodilator reversibility test}

Patients were asked to inhale $400 \mu \mathrm{g}$ salbutamol via a metered dose inhaler after baseline evaluation, and PFT was repeated not $<20$ minutes. Three forced expiratory maneuvers were recorded. The positive response, which was defined as $\mathrm{FEV}_{1}>200 \mathrm{~mL}$ and $\mathrm{FEV}_{1}>12 \%$ after salbutamol inhalation, was obtained. ${ }^{8}$ 


\section{Sputum induction}

Sputum was induced with hypertonic saline inhalation through an ultrasonic nebulizer. A single hypertonic saline $(3 \% \mathrm{NaCl})$ is used. Patients were asked to inhale $400 \mu \mathrm{g}$ salbutamol via a metered dose inhaler 20 minutes before induction. Collected lower respiratory sputum portions of induced sputum were dispersed using $0.1 \%$ dithiothreitol with a water bath $\left(37^{\circ} \mathrm{C}\right)$ and an oscillator 15 minutes before filtration through a 300-mesh nylon mesh filter, and subsequently total cell count was centrifuged, smeared and stained (hematoxylin-eosin). A differential cell count was obtained from 400 cells with a $400 \times$ microscope to identify the type of airway inflammation. A sputum eosinophil percentage of $\geq 2.5 \%$ was defined as abnormal. ${ }^{5}$

\section{Statistical analysis}

Data analysis was performed using SPSS version 19 (IBM Corporation, Armonk, NY, USA). The results were expressed as mean \pm SD for continuous variables and median with interquartile range for non-normally distributed variables. Categorical variables were reported using frequencies and percentages. Data were analyzed by the Student's $t$-test for quantitative variables and the chi-square test for categorical variables. Non-normally distributed variables were analyzed by the Mann-Whitney test. Spearman's rank correlation coefficient was used to assess the relationship between FeNO, sputum eosinophil percentage, BHR and bronchodilator reversibility. The performance characteristics of FeNO and sputum eosinophil percentage were examined by constructing receiver operating characteristic (ROC) curves to determine the optimal cutoff value of eosinophilic airway inflammation. $p$-values $<0.05$ were reported to be statistically significant.

\section{Results}

\section{Characteristics of the patients}

Patient demographic information is presented in Table 1. A total of 69 uncontrolled asthmatic patients participated (40 [57.97\%] males) in this study. The mean age was 58.86 years. Smokers accounted for $38.89 \%$ of patients. All patients were Chinese. PFT results are reported in Table 2. Patients had a mean $\mathrm{FEV}_{1} /$ forced vital capacity (FVC) $\%$ of $67.38 \% \pm 8.71 \%$ and a mean $\mathrm{FEV}_{1} \%$ pred of $82.01 \% \pm 11.94 \%$. The results of FeNO and induced sputum are reported in Table 3.

\section{Sputum induction}

The characteristics of patients are shown in Table 4. Patients in the S-eosinophilic group compared with patients in the
Table I Demographic and baseline characteristics of the patients

\begin{tabular}{ll}
\hline Demographic parameters & All participants (N=69) \\
\hline Mean age, years (SD) & $58.86(15.2)$ \\
$\quad$ Range & $18-85$ \\
Males, $\mathrm{n}(\%)$ & $40(57.97)$ \\
Race, $\mathrm{n}(\%)$ & \\
$\quad$ Chinese & $69(100)$ \\
Mean height, cm (SD) & $160(9.04)$ \\
$\quad$ Range & $136-174$ \\
Mean weight, $\mathrm{kg}(\mathrm{SD})$ & $58.7(8.83)$ \\
$\quad$ Range & $44.5-84$ \\
Mean body mass index, $\mathrm{kg} / \mathrm{m}^{2}$ (SD) & $22.89(3.22)$ \\
$\quad$ Range & $16.7 \mathrm{I}-32.98$ \\
Smokers, $\mathrm{n}(\%)$ & $27(39.13)$ \\
Pack-years, years (SD) & $45(31.47)$ \\
Allergic rhinitis, n (\%) & $8(11.59)$ \\
\hline
\end{tabular}

Note: $\mathrm{N}$ refers to the total population; $\mathrm{n}$ refers to the subgroup population.

Table 2 Spirometry results for the patients

\begin{tabular}{|c|c|}
\hline Variable postbronchodilator & All participants $(\mathrm{N}=69)$ \\
\hline FVC (L), mean (SD) & $3.04(0.93)$ \\
\hline $\mathrm{FEV}_{1}(\mathrm{~L})$, mean $(\mathrm{SD})$ & $2.03(0.6)$ \\
\hline $\mathrm{FEV}, \%$ predicted, mean (SD) & $82.01(11.94)$ \\
\hline $\mathrm{FEV}_{1} / \mathrm{FVC}(\%)$, mean (SD) & $67.38(8.7 I)$ \\
\hline PEF (L/min), mean (SD) & $5.39(1.78)$ \\
\hline PEF\% predicted, mean (SD) & $78.42(17.44)$ \\
\hline MMEF, mean (SD) & $1.38(0.52)$ \\
\hline MMEF\% predicted, mean (SD) & $40.16(18.89)$ \\
\hline MEF50\% (L/s), mean (SD) & $\mathrm{I} .75(0.75)$ \\
\hline MEF50\% predicted, mean (SD) & $46.95(21.12)$ \\
\hline MEF25\% (L/s), mean (SD) & $0.6 \mathrm{I}(0.28)$ \\
\hline MEF25\% predicted, mean (SD) & $45.92(20)$ \\
\hline
\end{tabular}

Abbreviations: FVC, forced vital capacity; FEV, forced expiratory volume in I second; PEF, peak expiratory flow; MMEF, maximum mid-expiratory flow; MEF, maximal expiratory flow.

Table 3 FeNO levels and induced sputum results for the patients

\begin{tabular}{ll}
\hline Variables & All participants $(\mathbf{N}=69)$ \\
\hline FeNO level (ppb) & $47(24,87)$ \\
Eosinophil (\%) & $5.78(1.95,19.3)$ \\
Neutrophil (\%) & $75.2(19.26)$ \\
Macrophage (\%) & $5.23(2.24,14.15)$ \\
\hline
\end{tabular}

Note: Values are expressed as median (interquartile range) or mean (SD).

Abbreviation: $\mathrm{FeNO}$, fractional exhaled nitric oxide.

S-noneosinophilic group showed a higher FeNO level (49 [29, 95] versus $27[19,48], p=0.011)$ and sputum neutrophil percentage (mean [SD] 71.12 [20] versus 87.67 [9.11], $p=0.012$ ).

\section{FeNO}

The characteristic of patients are shown in Table 5. Sputum eosinophil percentage was higher in the F-eosinophilic group than in the $\mathrm{F}$-noneosinophilic group $(p=0.03)$. 
Table 4 FeNO levels and sputum neutrophilic percentage results for the patients

\begin{tabular}{|c|c|c|c|}
\hline Variables & S-eosinophil $(n=52)$ & S-noneosinophil $(n=17)$ & p-value \\
\hline Mean age, years & $56.12(15.37)$ & $67.24(11.41)$ & 0.412 \\
\hline Males, n (\%) & $32(6 \mid .54)$ & $8(47.06)$ & 0.294 \\
\hline $\mathrm{BMI}, \mathrm{kg} / \mathrm{m}^{2}$ & $22.87(3.86)$ & $22.96(2.8 I)$ & 0.566 \\
\hline Smokers, n (\%) & $22(42.31)$ & $5(29.4 I)$ & 0.344 \\
\hline Postbronchodilator $\mathrm{FEV}$ \% predicted & $80.62(8.53)$ & $86.26(18.68)$ & 0.06 \\
\hline Postbronchodilator $\mathrm{FEV}_{1}(\mathrm{~L})$ & $2.12(0.6)$ & $\mathrm{I} .74(0.5 \mathrm{I})$ & 0.329 \\
\hline Postbronchodilator FEV,/FVC (\%) & $66.69(8.77)$ & $69.46(8.44)$ & 0.747 \\
\hline $\mathrm{PEF}(\mathrm{L} / \mathrm{min})$ & $5.76(1.74)$ & $4.25(1.4)$ & 0.12 \\
\hline FeNO level, ppb & $49(29,95)$ & $27(19,48)$ & 0.011 \\
\hline Neutrophilic\% & $71.12(20)$ & $87.67(9.11)$ & 0.012 \\
\hline Macrophage\% & $5.15(2.05,13.4)$ & $9.6(2.35,17.76)$ & 0.592 \\
\hline
\end{tabular}

Notes: S-eosinophil refers to sputum eosinophil count $\geq 2.5 \%$; S-noneosinophil refers to sputum eosinophil count $<2.5 \%$. Significant $p$-value $<0.05$ are shown in bold. Abbreviations: BMI, body mass index; FeNO, fractional exhaled nitric oxide; FVC, forced vital capacity; FEV , forced expiratory volume in I second; PEF, peak expiratory flow.

Table 5 Sputum eosinophil and neutrophil percentage result for the patients

\begin{tabular}{|c|c|c|c|}
\hline Variables & F-eosinophilic $(n=45)$ & F-noneosinophilic $(n=24)$ & $p$-value \\
\hline Mean age, years & $54.98(15.59)$ & $66.13(11.55)$ & 0.262 \\
\hline Males, n (\%) & $27(60)$ & $13(54.17)$ & 0.64 \\
\hline BMI, kg/m² (SD) & $22.32(3.13)$ & $23.96(3.17)$ & 0.829 \\
\hline Smokers, n (\%) & $16(35.56)$ & II (45.83) & 0.405 \\
\hline Postbronchodilator $\mathrm{FEV} \%$ predicted & $81.56(12.58)$ & $82.3(10.9)$ & 0.908 \\
\hline Postbronchodilator FEV (L) & $2.13(0.55)$ & $1.84(0.66)$ & 0.166 \\
\hline Postbronchodilator $\mathrm{FEV}_{1} / \mathrm{FVC}(\%)$ & $67.67(8.89)$ & $66.83(8.53)$ & 0.64 \\
\hline $\operatorname{PEF}(\mathrm{L} / \mathrm{min})$ & $5.64(I .7 I)$ & $4.91(1.83)$ & 0.766 \\
\hline Eosinophilic\% & $10.3(3.8,22.68)$ & $2.75(0.3,8.35)$ & 0.03 \\
\hline Neutrophilic\% & $70.93(20.5 \mathrm{I})$ & $83.2(13.77)$ & 0.049 \\
\hline Macrophage\% & $6.2(2.13,17.89)$ & $5.17(2.3,12.34)$ & 0.508 \\
\hline
\end{tabular}

Notes: F-eosinophilic refers to FeNO level $\geq 32 \mathrm{ppb}$; F-noneosinophilic refers to FeNO level $<32 \mathrm{ppb}$. Significant $p$-value $<0.05$ are shown in bold. Abbreviations: BMI, body mass index; FVC, forced vital capacity; FEV $_{1}$, forced expiratory volume in I second; PEF, peak expiratory flow.

\section{Correlation between FeNO levels, sputum eosinophil percentage, BHR and bronchodilator reversibility}

A significant correlation was observed between sputum eosinophilic\% and FeNO levels $(r=0.4016 ; p=0.0006)$ (Figure 1E). There were no significant relationships between sputum eosinophil percentage and $\mathrm{PD}_{20}(p=0.1451)$ (Figure 1A); FeNO levels and $\mathrm{PD}_{20}(p=0.1062)$ (Figure 1B); sputum eosinophil percentage and $\triangle \mathrm{FEV}_{1}(p=0.1816)$ (Figure 1C); and FeNO levels and $\Delta \mathrm{FEV}_{1}(p=0.3877)$ (Figure 1D).

ROC curve analysis demonstrated that $4.36 \%$ was the best diagnostic cutoff value of sputum eosinophilic\% for $32 \mathrm{ppb}$ of FeNO level (area under curve [AUC] 0.721; 95\% confidence interval [CI] 0.59-0.852). Sensitivity and specificity were $71.1 \%$ and $70.8 \%$, respectively (Figure $2 \mathrm{~A}$ ). In addition, FeNO levels were effective in assessing sputum eosinophilia, with an ROC AUC of 0.707 ( $p=0.011$; 95\% CI $0.573-0.841$ ), using $35.5 \mathrm{ppb}$ as the best threshold, as reported in the external validation cohort. Sensitivity and specificity were $69.2 \%$ and $70.6 \%$, respectively (Figure 2B).

\section{Discussion}

In the present study, the correlation of FeNO level and sputum eosinophil in uncontrolled asthma was assessed. The included asthmatic patients $(\mathrm{N}=69)$ were initially diagnosed with uncontrolled stage. All participants were Chinese.

Following the 2016 recommendation of the Chinese National Guidelines on Diagnosis and Management of Cough, eosinophilic airway inflammation was defined as a sputum eosinophil percentage of $\geq 2.5 \%$, and the results of FeNO level and sputum neutrophil percentage were different, as shown in Table 4. Induced sputum cell counts are the "gold standard" test for defining airway inflammatory phenotype. ${ }^{9}$ However, the induced sputum cell counts is limited, and measurement of FeNO has achieved wide acceptance in clinical practice because it is a simpler method to assess airway inflammation. 
A

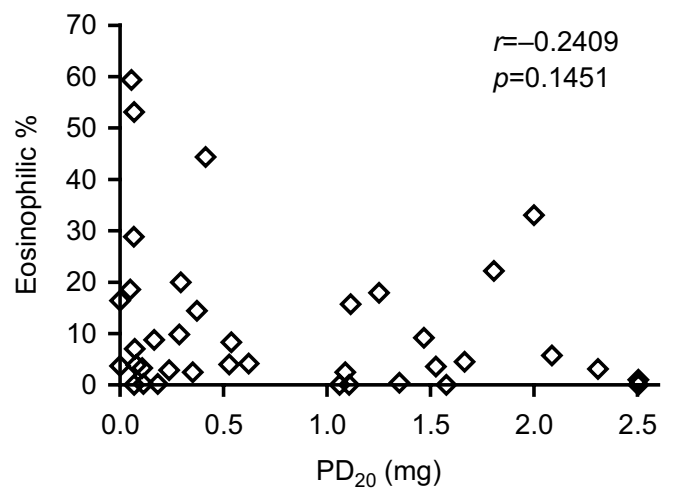

C

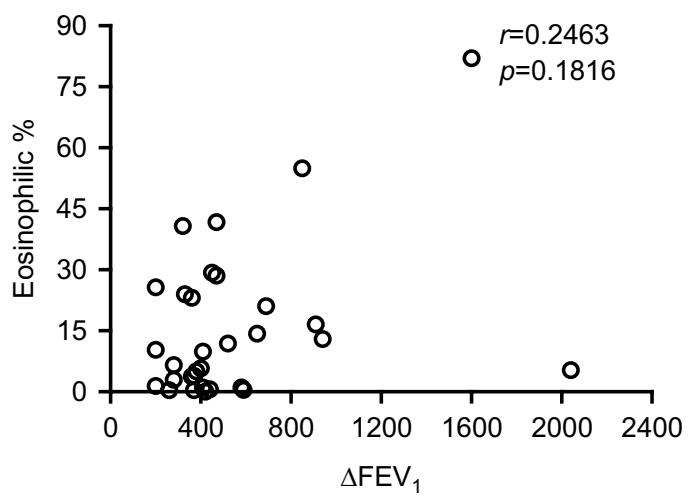

B

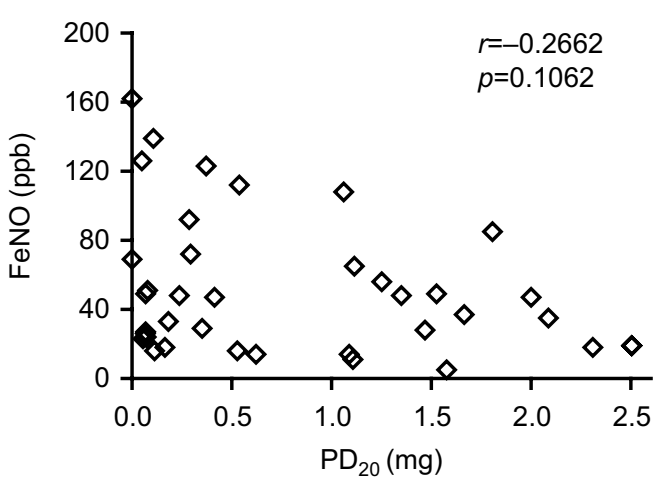

D

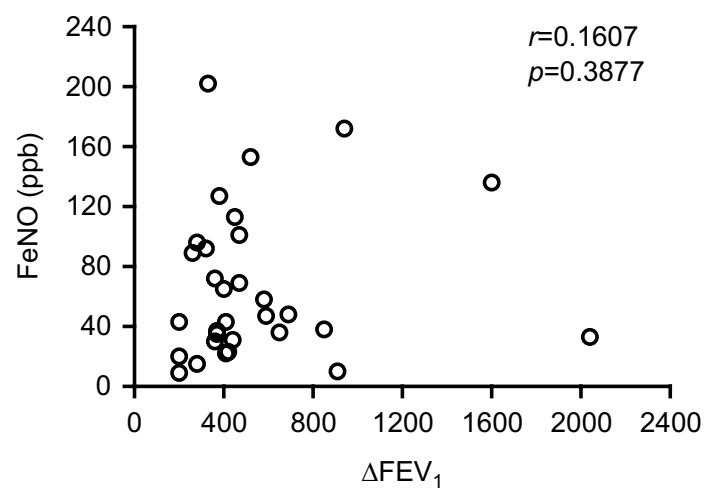

$r=0.4016$

$p=0.0006$

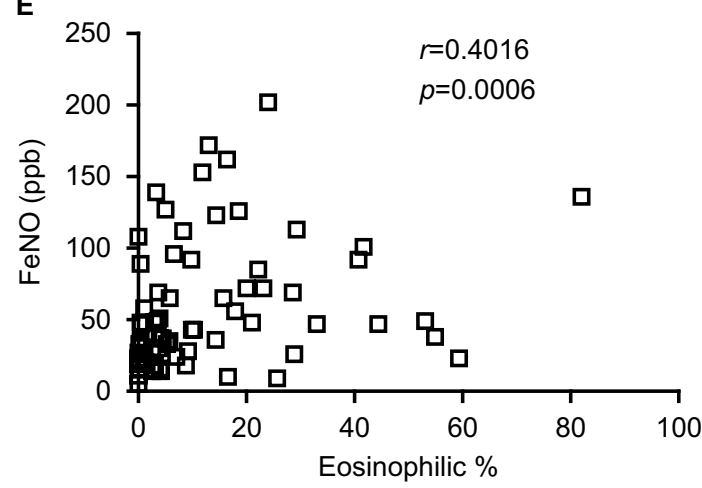

Figure I Scatter plots of relationship between sputum eosinophil, FeNO, BHR and bronchodilator reversibility

Notes: (A) Correlation between sputum eosinophil percentage and $\mathrm{PD}_{20}(\mathrm{mg})$. (B) Correlation between FeNO level and $\Delta \mathrm{FEV}$, (mL). $(\mathbf{C})$ Correlation between sputum eosinophil percentage and $\Delta \mathrm{FEV},(\mathrm{mL})$. (D) Correlation between FeNO level and $\Delta \mathrm{FEV},(\mathrm{mL}) ; \Delta$, improvement in FEV after $400 \mu \mathrm{g}$ of salbutamol. (E) Correlation between FeNO level and sputum eosinophil percentage.

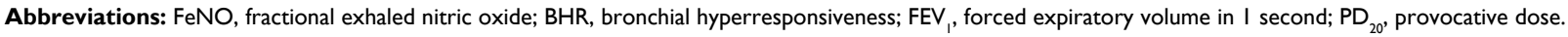

The 2016 guideline also suggested that a significant sputum eosinophilia $(\geq 2.5 \%)$ was considered if the FeNO level was $\geq 32 \mathrm{ppb},{ }^{5}$ and the results of the sputum eosinophil and neutrophil percentage were different, as shown in Table 5. However, the $p$-value ( $p=0.049$ ) changed slightly under 0.05 , and the differentiation was very low in sputum neutrophil. The given number of data points may not be taken as strong evidence for such a difference. It is possible that FeNO levels do not predict neutrophilic asthma in clinical practice.
The correlation between FeNO levels and sputum eosinophils, even though not strong, suggests a causal link. The relationship suggests that NO derived from airway epithelial cells and inflammatory cells is increased due to induction of NO synthase (NOS) by the exposure to pro-inflammatory cytokines. Such a large amount of NO has been reported to result in suppression of Th1 cells and a concomitant reduction in the level of IFNc, leading to a proliferation of Th2 cells. Th2 cells then produce several cytokines including 

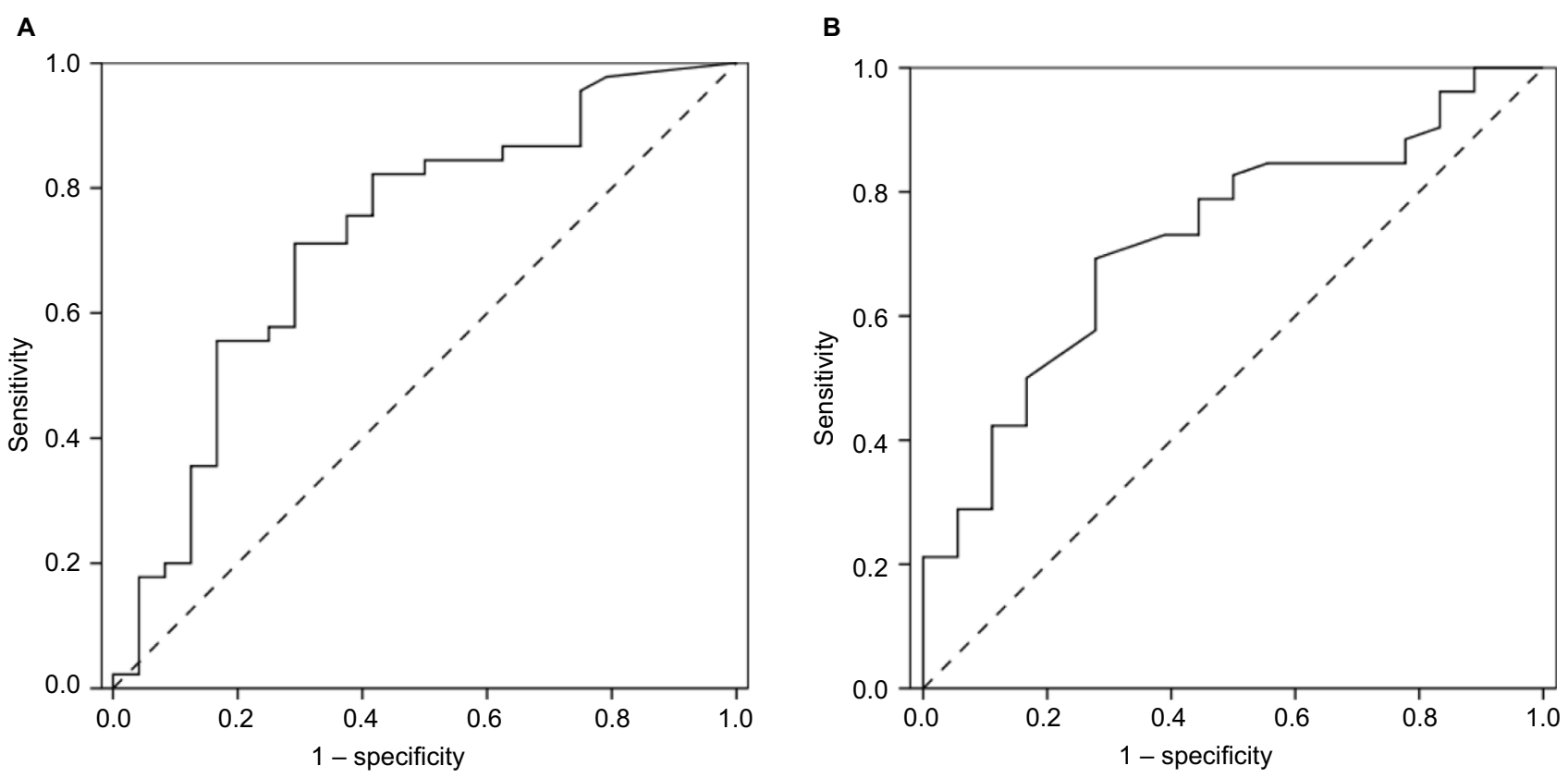

Figure 2 ROC curve for sputum eosinophil percentage versus FeNO level (A) and FeNO level versus sputum eosinophil percentage (B).

Abbreviations: FeNO, fractional exhaled nitric oxide; ROC, receiver operating characteristic.

IL-5 which is important in the recruitment of eosinophils into the airways. ${ }^{10}$ Although in the clinical setting there is a positive correlation between FeNO levels and sputum eosinophils in eosinophilic asthma, sometimes there is a discrepancy between the results of these methods, with high FeNO values and sputum eosinophils within reference levels and vice versa, independently of the level of asthma control and treatment. May be there are mechanisms more complex and different from the classic Th2 pathway that may explain this dissociation.

No significant correlation was found between the percentage of sputum eosinophils and $\mathrm{PD}_{20}$; FeNO levels and $\mathrm{PD}_{20}$; the percentage of sputum eosinophils and $\triangle \mathrm{FEV}_{1}$; and FeNO levels and $\triangle \mathrm{FEV}_{1}$. Failure to demonstrate such a relationship could have been due to either a small sample size or narrow ranges of $\triangle \mathrm{FEV}_{1}$ and $\mathrm{PD}_{20}$ measured, or both.

The ROC results have shown that the FeNO level (35.5 ppb) was used to distinguish the patients with sputum eosinophilia from those without. The cutoff point is higher than 32 ppb (2016 Chinese Guidelines), and it is possible that the asthmatic patients are in uncontrolled stage in this study. However, the optimal cutoff point was in dispute because normal or low FeNO does not exclude airway eosinophilia, and their sensitivity and/or specificity is often suboptimal compared to that of reference standard tests. Although the two methods are useful to assess airway inflammation in clinical practice, there are confounding factors to affect FeNO in many cases. Furthermore, FeNO has a limited value to assess noneosinophilic airway inflam- mation, and bronchial sputum cytology provides a more accurate approximation of airway inflammatory phenotypes in asthmatic patients.

\section{Conclusion}

This study provides that the FeNO level can accurately detect eosinophilic uncontrolled asthma but has limited value to assess noneosinophilic airway inflammatory. The data may be useful to help guide treatment and management of eosinophilic asthma patients using corticosteroid. However, further studies are required to validate the use of FeNO level to determine an optimal cutoff for sputum eosinophilia that could be used in clinical practice.

\section{Acknowledgment}

The study was supported by Health and Family Planning Commission of Guangdong, People's Republic of China (grant ID: A2017535).

\section{Disclosure}

The authors report no conflicts of interest in this work.

\section{References}

1. Gibson PG. Inflammatory phenotypes in adult asthma: clinical applications. Clin Respir J. 2009;3:198-206.

2. Wenzel S, Ford L, Pearlman D, et al. Dupilumab in persistent asthma with elevated eosinophil levels. $N$ Engl J Med. 2013;368(26):2455-2466.

3. Donohue JF, Herje N, Crater G, Rickard K. Characterization of airway inflammation in patients with COPD using fractional exhaled nitric oxide levels: a pilot study. Int J Chron Obstruct Pulmon Dis. 2014;16:745-751. 
4. Dweik RA, Boogs PB, Erzurum SC, et al. An official ATS clinical practice guideline: interpretation of exhaled nitric oxide levels (FENO) for clinical applications. Am J Respir Crit Care Med. 2011;184(5):602-615.

5. Asthma Workgroup of Chinese Society of Respiratory Diseases (CSRD), Chinese Medical Association. The Chinese national guidelines on diagnosis and management of cough (2015). Chin J Tuberc Respir Dis. 2016;39:321-339. Available from: http://zhjhhhxzz.yiigle.com/ CN112147201605/892423.htm. Accessed March 01, 2018.

6. Global Initiative for Asthma [webpage on the Internet]. Global Strategy for Asthma Management and Prevention. Available from: http:// ginasthma.org/2017-pocket-guide-for-asthma-management-andprevention/. Accessed January 19, 2017.
7. American Thoracic Society, European Respiratory Society. ATS/ERS recommendations for standardized procedures for the online and offline measurement of exhaled lower respiratory nitric oxide and nasal nitric oxide, 2005. Am Respir Crit Care Med. 2005;171(8):912-930.

8. The Chinese national guidelines of pulmonary function test (2014). Chin J Tuberc Respir Dis. 2014;37(8):566-571. Available from: http://zhjhhhxzz. yiigle.com/CN112147201408/860037.htm. Accessed March 01, 2018.

9. Djukanović R, Sterk PJ, Fahy JV, Hargreave FE. Standardised methodology of sputum induction and processing. Eur Respir J. 2002; 20(Suppl 37):1s-2s.

10. Barnes PJ, Liew FY. Nitric oxide and asthmatic inflammation. Immunol Today. 1995;16:128-130.
Journal of Asthma and Allergy

\section{Publish your work in this journal}

The Journal of Asthma and Allergy is an international, peer-reviewed open access journal publishing original research, reports, editorials and commentaries on the following topics: Asthma; Pulmonary physiology; Asthma related clinical health; Clinical immunology and the immunological basis of disease; Pharmacological interventions and

\section{Dovepress}

new therapies. This journal is included in PubMed. The manuscript management system is completely online and includes a very quick and fair peer-review system, which is all easy to use. Visit http://www. dovepress.com/testimonials.php to read real quotes from published authors. 